\title{
Ursolic Acid Inhibits Epithelial-Mesenchymal Transition through the Axl/NF- $\kappa$ B Pathway in Gastric Cancer Cells
}

\author{
Jinxia Li $\mathbb{D}^{1},{ }^{1}$ Chunyan Dai, ${ }^{2}$ and Li Shen ${ }^{3}{ }^{3}$ \\ ${ }^{1}$ Hunan University of Chinese Medicine, Changsha 410208, China \\ ${ }^{2}$ Zhejiang Key Laboratory of Gastro-Intestinal Pathophysiology, Zhejiang Hospital of Traditional Chinese Medicine, \\ Zhejiang Chinese Medicine University, Hangzhou 310006, China \\ ${ }^{3}$ Institute of Basic Theory of TCM, China Academy of Chinese Medical Sciences, Beijing 100700, China
}

Correspondence should be addressed to Li Shen; shenli1116@126.com

Received 2 March 2019; Revised 12 May 2019; Accepted 20 May 2019; Published 9 June 2019

Academic Editor: Michał Tomczyk

Copyright (c) 2019 Jinxia Li et al. This is an open access article distributed under the Creative Commons Attribution License, which permits unrestricted use, distribution, and reproduction in any medium, provided the original work is properly cited.

Background. Ursolic acid (UA) is an antitumor component derived from Chinese herbal medicine; this study is to observe the effects of UA on epithelial-mesenchymal transition (EMT) in gastric cancer. Methods. (1) In vitro experiments: $25 \mu \mathrm{mol} / \mathrm{L}$ and $50 \mu \mathrm{mol} / \mathrm{L}$ UA were applied to BGC-823, AGS, MGC-803, and HGC-27 cells; MTT staining, Transwell assay, and flow cytometry were used to assess cell proliferation, cell migration, and apoptosis, respectively. Western blot was performed to detect the expressions of $\mathrm{N}$-Cadherin, Vimentin, Snail, Twist, Axl, p-Axl, IKK, p-IKK, NF- $\kappa$ B, and p-NF- $\kappa$ B. (2) In vivo experiments: Ten BALB/c-nu mice were used to establish gastric cancer xenograft model. Five were orally given UA for 4 weeks and five were given normal saline. Expressions of N-Cadherin and Snail were examined by immunohistochemical assay; expressions of N-Cadherin, Snail, Twist, Axl, p-Axl, IKK, and p-IKK were detected by Western blot. Results. (1) UA inhibited cell proliferation in BGC-823 and HGC-27 cells in dose-dependent manners. (2) UA inhibited cell migration in BGC-823, AGS, and MGC-803 cells while inducing apoptosis in BGC823 cells. (3) UA significantly decreased the expressions of N-Cadherin, Vimentin, Snail, Twist p-Axl, p-IKK $\alpha / \beta$, and $p-N F-\kappa B$ in BGC-823 and MGC-803 cells. (4) UA distinctly decreased the expressions of N-Cadherin, Snail, p-Axl, and p-IKK $\alpha / \beta$ in gastric cancer xenograft model rats. Conclusion. UA can effectively inhibit the proliferation and migration and induce apoptosis of gastric cancer cells. The antitumor effect of UA is conducted by EMT inhibition, which may be associated with the regulation of Axl/NF- $\kappa \mathrm{B}$ signaling pathway.

\section{Background}

Gastric carcinoma (GC) is the fourth most common malignant tumor throughout world, and it is the second leading cause of cancer mortality [1]. In China, the incidence of GC ranks third among all malignant tumors; there are 380,000 new cases annually [2]. The prognosis of GC is closely related to early detection, invasion, and metastasis which account for more than $90 \%$ of the causes of death [3]. Therefore, prevention of tumor invasion and metastasis may improve the early detection and prognosis of GC.

The epithelial-mesenchymal transition (EMT) is a process through which epithelial cells are converted into mesenchymal cells; it is characterized as the loss of cell-cell adhesion and cell polarity, the acquisition of migratory and invasive properties, and the improvement of resistance to apoptosis and degradation of extracellular matrix [4]. Therefore, aberrant activation of EMT plays a crucial role in the genesis, invasion, and metastasis of various tumors, including GC [5].

Ursolic acid (UA) is an antitumor component derived from Chinese herbal medicine. The structural formula is shown in Figure 1. It could inhibit cell proliferation and induce apoptosis in a variety of tumor cells [6]. Previous studies demonstrated that UA can induce apoptosis and inhibit proliferation of GC [7-9]; hence we hypothesize that UA can prevent GC invasion and metastasis by inhibiting EMT.

In this study, we conducted both in vivo and in vitro experiments to observe the effects of UA on EMT in GC. In in 


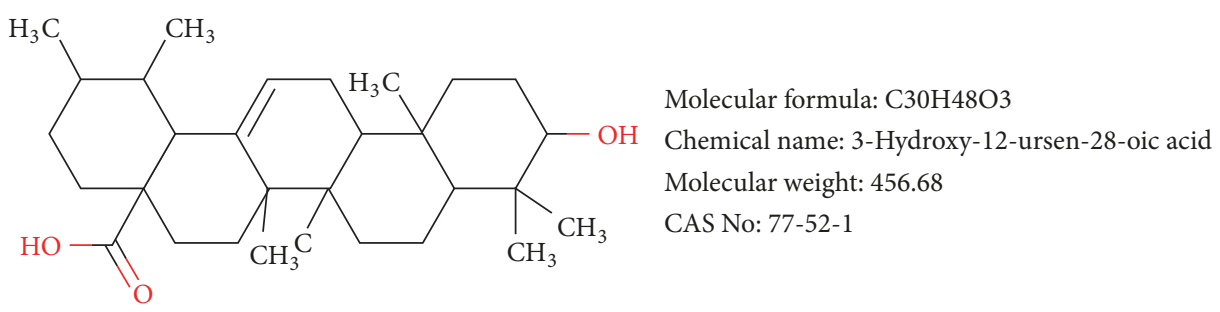

Figure 1: Structural formula of ursolic acid.

vitro experiment, BGC-823, AGS, MGC-803, NCI-N87, and HGC-27 cells were used; MGC-803 represents high differentiation stage of GC, BGC-823 and AGS represent poorly differentiated GC, HGC-27 represents undifferentiated GC, and NCI-N87 represents fore-GC. In in vivo experiment, gastric cancer xenograft mice model was used, since it well simulates the pathogenesis and pathological change of human gastric cancer.

\section{Methods}

\subsection{In Vitro Experiments}

2.1.1. Cell Culture. Gastric cancer cell lines BGC-823, HGC27, AGS, MGC-803, and NCI-N87 were from Central Research Center, Zhejiang Province Hospital of Traditional Chinese Medicine.

After cell resuscitation, cells were inoculated in a $25 \mathrm{~cm}^{2}$ cell culture flask with a density of $2 \times 10^{6} / \mathrm{mL}$. Cells were maintained in RPMI-1640 medium with $10 \%$ calf serum and grew at $37^{\circ} \mathrm{C}$ in a $\mathrm{CO}_{2}$ incubator. Cells in logarithmic growth phase were collected for following experiments.

2.1.2. Cell Proliferation Assay by MTT Staining. $250 \mu \mathrm{L}$ of BGC-823 and HGC-27 $\left(3 \times 10^{5} / \mathrm{mL}\right)$ were added to each well in the 96-well plate. UA was added to the final concentration of $6.25 \mu \mathrm{mol} / \mathrm{L}, 12.5 \mu \mathrm{mol} / \mathrm{L}, 25 \mu \mathrm{mol} / \mathrm{L}, 50 \mu \mathrm{mol} / \mathrm{L}$, and $100 \mu \mathrm{mol} / \mathrm{L}$, respectively. Dimethyl sulfoxide and culture medium were added as control. $10 \mu \mathrm{L}$ Cell Counting Kit-8 was added, plates were lucifuge incubated in $37^{\circ} \mathrm{C}$ for $1 \mathrm{~h}$, and the absorbance values were examined. The inhibiting proliferation rates were calculated using the following equation: Inhibiting proliferation rate $(\%)=$ (a value of control group - a value of treated group)/ a value of control group $\times 100 \%$.

2.1.3. Cell Migration Assay by Transwell. $100 \mu \mathrm{L}$ of AGS, HGC27, MGC-803, and NCI-N87 were inoculated in the upper chambers, and the cell density was adjusted to $1.5 \times 10^{4} / \mathrm{mL}$ and $2 \times 10^{4} / \mathrm{mL}$, respectively. $500 \mu \mathrm{L}$ of culture medium with $10 \%$ calf serum was added in the lower chambers; the chambers were incubated at $37^{\circ} \mathrm{C}, 5 \% \mathrm{CO}_{2}$ for $24 \mathrm{~h}$, then rinsed with phosphate buffer saline, fixed with $4 \%$ formalin for $20 \mathrm{~min}$, and crystal violet stained for $20 \mathrm{~min}$. Cotton swabs were used to remove the cells that are unable to penetrate the membrane surface. Photograph under $200 \times$ magnification and count the number of migrated cells.
According to the above experimental results, $10 \mu \mathrm{L}$ of UA was added to AGS, MGC-803, and BGC-823 cells with the final concentration of $25 \mu \mathrm{mol} / \mathrm{L}$ and $50 \mu \mathrm{mol} / \mathrm{L}$, respectively; after incubation for $24 \mathrm{~h}$, the Transwell assay was performed again according to the above steps.

2.1.4. Cell Apoptosis Assay by Flow Cytometry. BGC-823, MGC-803, and AGS cells $\left(1.5 \times 10^{5} / \mathrm{mL}\right)$ were treated with UA at concentration of $50 \mu \mathrm{mol} / \mathrm{L}$ for $24 \mathrm{~h}$. Cells were collected after centrifugation, $300 \mu \mathrm{L} 1 \times$ Binding Buffer was added to resuspend the cells, $5 \mu \mathrm{L}$ Annexin V-FITC Early Apoptosis Detection Kit (bioSmile), and $5 \mu \mathrm{L}$ propidine iodide was added and lucifuge incubated for $15 \mathrm{~min}$ and $5 \mathrm{~min}$ under room temperature, respectively. Then $200 \mu \mathrm{L}$ $1 \times$ Binding Buffer was replenished; flow cytometry was used for apoptosis analysis.

2.1.5. Western Blot Analysis. BGC-823, MGC-803, and AGS cells $\left(2 \times 10^{5} / \mathrm{mL}\right)$ were treated with $25 \mu \mathrm{mol} / \mathrm{L}$ and $50 \mu \mathrm{mol} / \mathrm{L}$ UA; expressions of N-Cadherin, Vimentin, Snail, Twist, $\mathrm{Axl}, \mathrm{p}-\mathrm{Axl}, \mathrm{IKK} \alpha / \beta, \mathrm{p}-\mathrm{IKK} \alpha / \beta, \mathrm{NF}-\kappa \mathrm{B}$, and $\mathrm{p}-\mathrm{NF}-\kappa \mathrm{B}$ were examined by Western blot. Cells were treated with RIPA Lysis Buffer ( $1 \%$ deoxycholate, $0.1 \%$ sodium dodecyl sulfate). Concentrations of proteins were determined by bicinchoninic acid assay. Proteins were separated by sodium dodecyl sulfate-polyacrylamide gel electrophoresis and incubated with proper primary and secondary antibodies. Then the proteins were transferred to polyvinylidene fluoride membrane, and the integrated option density was detected by far infrared scanner (ChemiDocTM Touch Imaging System, Bio-Rad) and Image $\mathrm{J}$ software. The relative expressions of proteins were calculated by using $\beta$-actin as an internal control.

\subsection{In Vivo Experiments}

2.2.1. Animals. Fourteen male BALB/c-nu mice weighing 17 20g were purchased and fed in animal experiment center of Zhejiang University of Traditional Chinese Medicine. Animals were housed in a specific pathogen free grade environment and fed with normal water and food. All procedures were under the approval of the Laboratory Animal Management and Welfare Ethical Review Committee of Zhejiang University of Traditional Chinese Medicine (Registration No. ZSLL-2017-1015).

2.2.2. Mouse Model and Grouping. Establishment of subcutaneous xenograft tumors: $5 \times 10^{7} / \mathrm{mL}$ of BGC-823 cell 

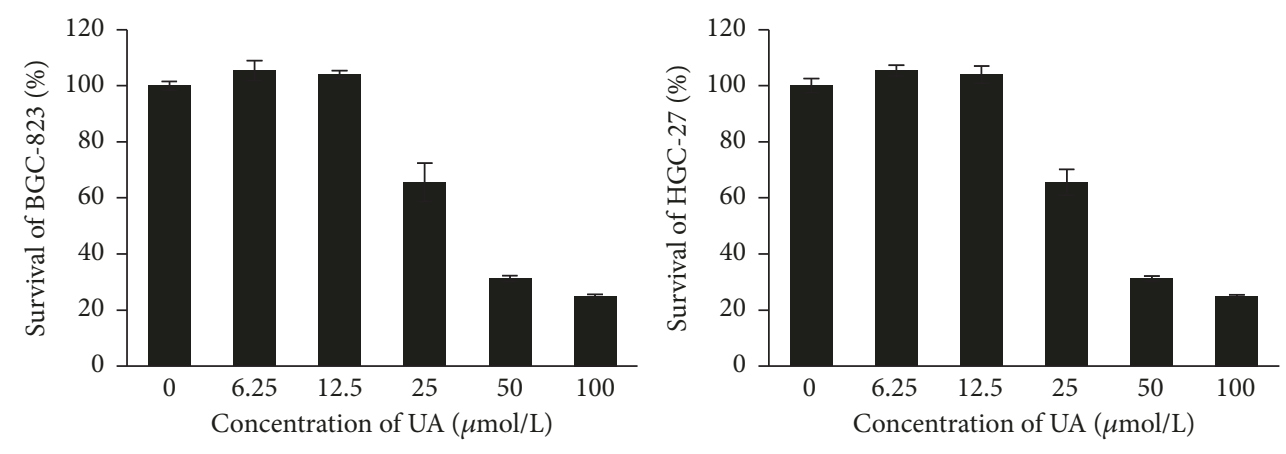

(a)
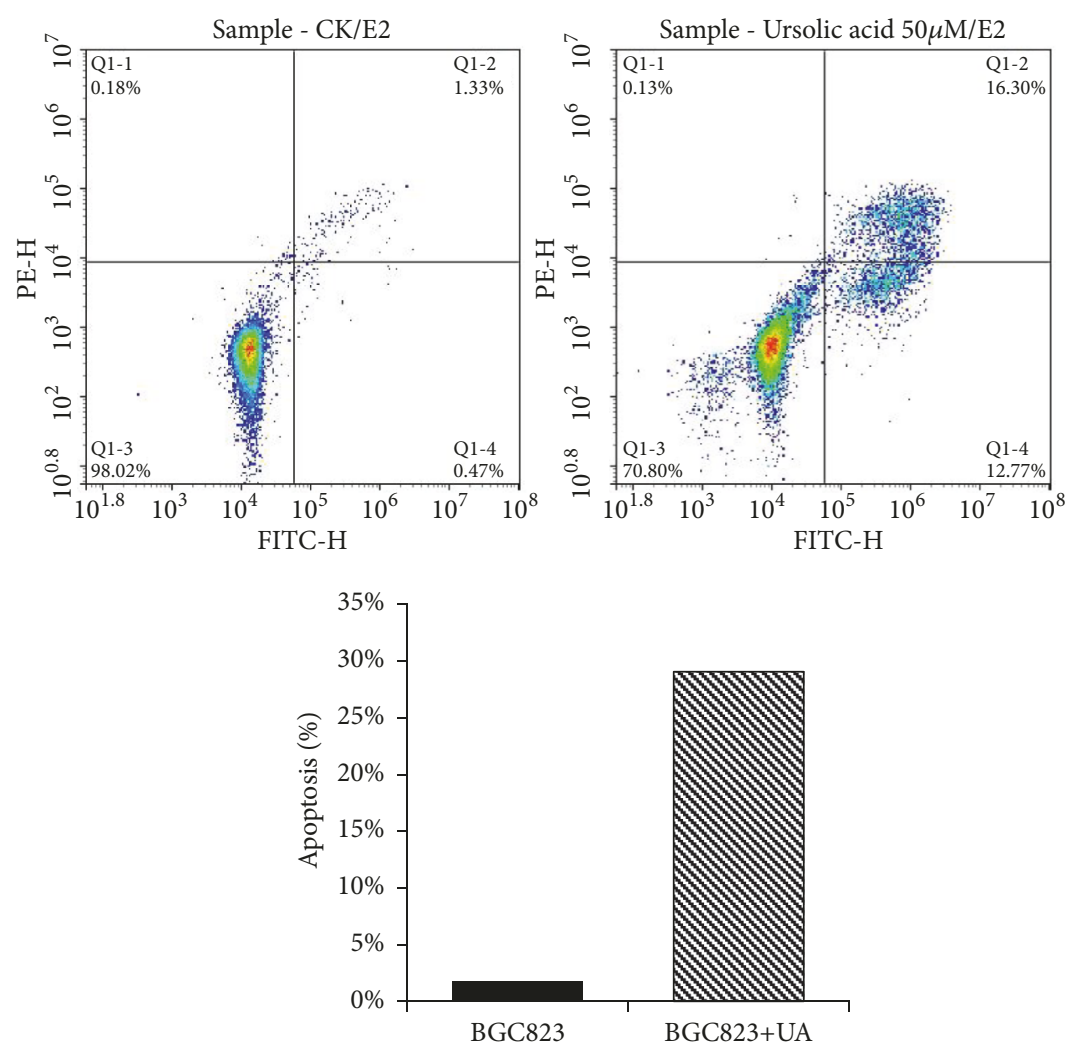

(b)

FIGURE 2: UA suppressed cell growth and induced apoptosis in gastric cancer cells. Note: Q1-1: necrotic cells; Q1-2: advanced apoptotic cells; Q1-3: normal cells; Q1-4: early apoptosis cells. Apoptosis rate\%= early apoptosis rate\% + advanced apoptosis rate\%.

suspension was injected into the axillary skin of $4 \mathrm{BALB} / \mathrm{c}-$ nu mice; condition was observed every 3 days. After 2 weeks, mice were sacrificed by carbon dioxide euthanasia when the tumor grew to a diameter of $1 \mathrm{~cm}$. The underarm skin was routinely disinfected; the tumor tissues were peeled and cut into small pieces about $1 \mathrm{~mm}^{3}$.

Establishment of GC xenograft model: Ten nude mice were anaesthetized by intraperitoneal injection of pentobarbital sodium peritoneal $(50 \mathrm{mg} / \mathrm{kg})$; a $0.2 \mathrm{~cm}$ long incision was cut in the right anterior armpit. The tumor was then implanted into the incision and a drop of $\mathrm{OB}$ glue was put to bind the incision. The condition of mice was observed every day to determine the tumorigenesis. At $72 \mathrm{~h}$ after successful modeling, mice were randomly divided into the model group and UA group; each has 5 mice. UA group was orally given UA $50 \mathrm{mg} / \mathrm{kg} / \mathrm{d}$, and corresponding saline was given to the model group for four weeks. Under anesthesia by pentobarbital sodium, the tumor tissues were removed, and mice were sacrificed by carbon dioxide euthanasia.

2.2.3. Immunohistochemical Analysis. Expressions of $\mathrm{N}$ Cadherin and Snail in mouse GC xenograft model were examined by immunohistochemistry staining. Sections were routinely dewaxed and hydrated. After the heat-mediated antigen retrieval, the sections were blocked with $10 \%$ goat serum at $37^{\circ} \mathrm{C}$ for $1 \mathrm{~h}$. Then the sections were incubated with primary antibody (1:800) at $4^{\circ} \mathrm{C}$ overnight. Polink-1 horse 

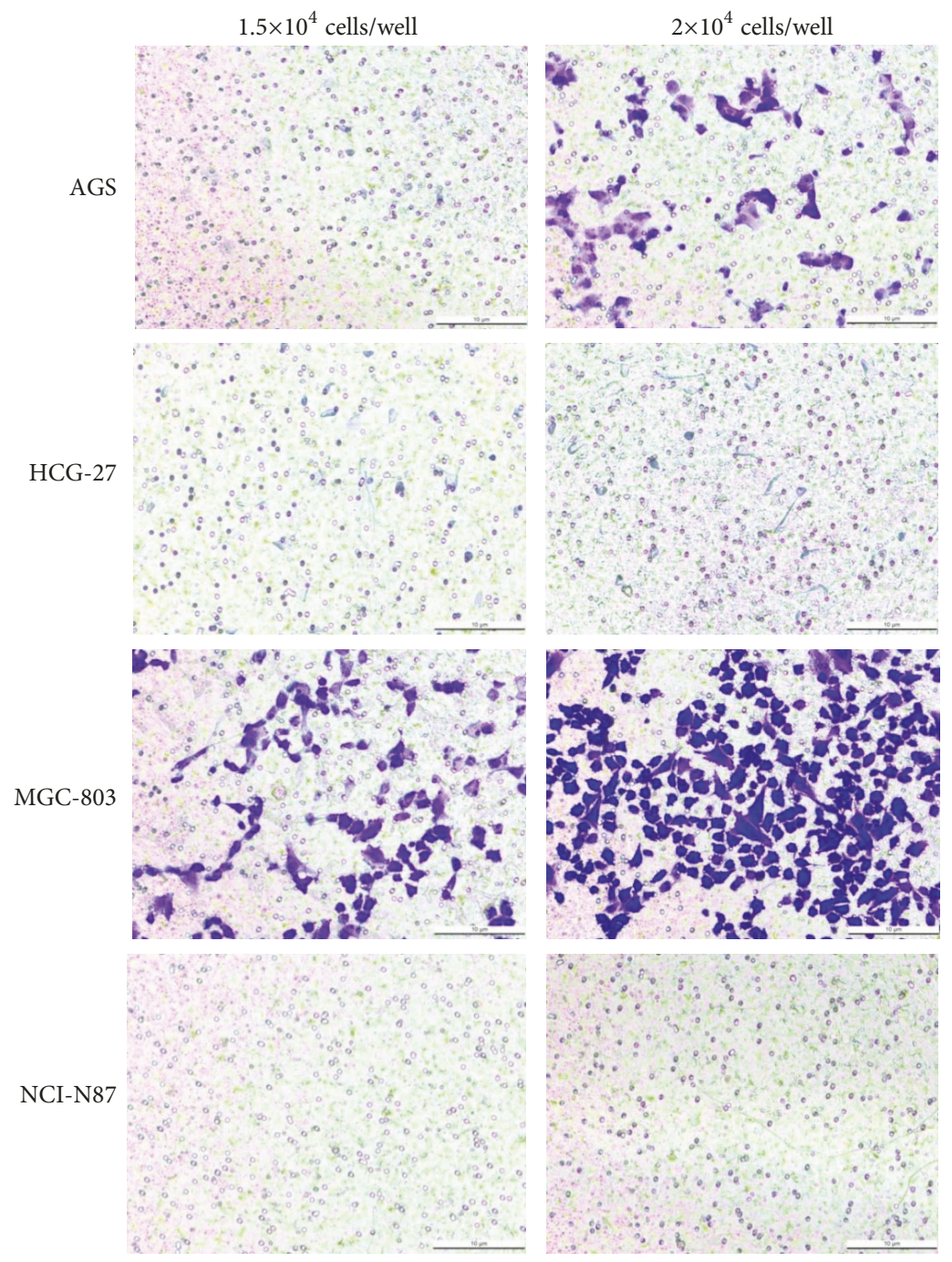

Figure 3: Cell migration capacity of AGS, HGC-27, MGC-803, and NCI-N87 cells.

radish peroxidase-diaminobenzidine 3 detection system was used to incubate the sections at $37^{\circ} \mathrm{C}$ for $1 \mathrm{~h}$, followed by diaminobenzidine 3 coloration and haematoxylin restaining. The integral optical density was analyzed by Image Pro Plus 6.0 software.

2.2.4. Western Blot Analysis. Expressions of N-Cadherin, Snail, Axl, $\mathrm{p}-\mathrm{Axl}, \mathrm{IKK} \alpha / \beta$, and $\mathrm{p}-\mathrm{IKK} \alpha / \beta$ in mouse GC xenograft model were determined by Western blot. Tumor tissues were homogenized, and the following operations were as same as above.

2.3. Statistical Analysis. Statistical analysis was performed by using SPSS19.0 software. Data were presented as mean \pm SD. One-way ANOVA was used for comparison between groups. Least-significant difference test was applied when the variance was equal; otherwise Tamhane's T2 test was performed. A value of $\mathrm{P}<0.05$ was considered to be statistically significant.

\section{Results}

3.1. UA Inhibited Cell Proliferation and Induced Apoptosis in Gastric Cancer Cells. Proliferation of BGC-823 and HGC27 cells was examined to assess the inhibitory effect on cell growth of UA. As shown in Figure 2(a), compared with control group, UA $(25-100 \mu \mathrm{mol} / \mathrm{L})$ inhibited cell proliferation in dose-dependent manners both in BGC-823 and in HGC27 cells.

Apoptosis in BGC-82, MGC-803, and AGS cells was assessed by flow cytometry. As shown in Figure 2(b) the apoptosis rate of normal BCG-823 cells was 1.80\%; after $50 \mu \mathrm{mol} / \mathrm{L}$ UA was added, the apoptosis rate increased to $29.07 \%$, which indicates that UA can significantly induce apoptosis in BGC-823 cells. UA damaged MGC-803 and AGS cells too much to obtain corresponding result.

3.2. Cell Migration Capacity of AGS, HGC-27, MGC-803, and NCI-N87 Cells. The cell migration capacity was analyzed by Transwell assay. As shown in Figure 3, AGS and 

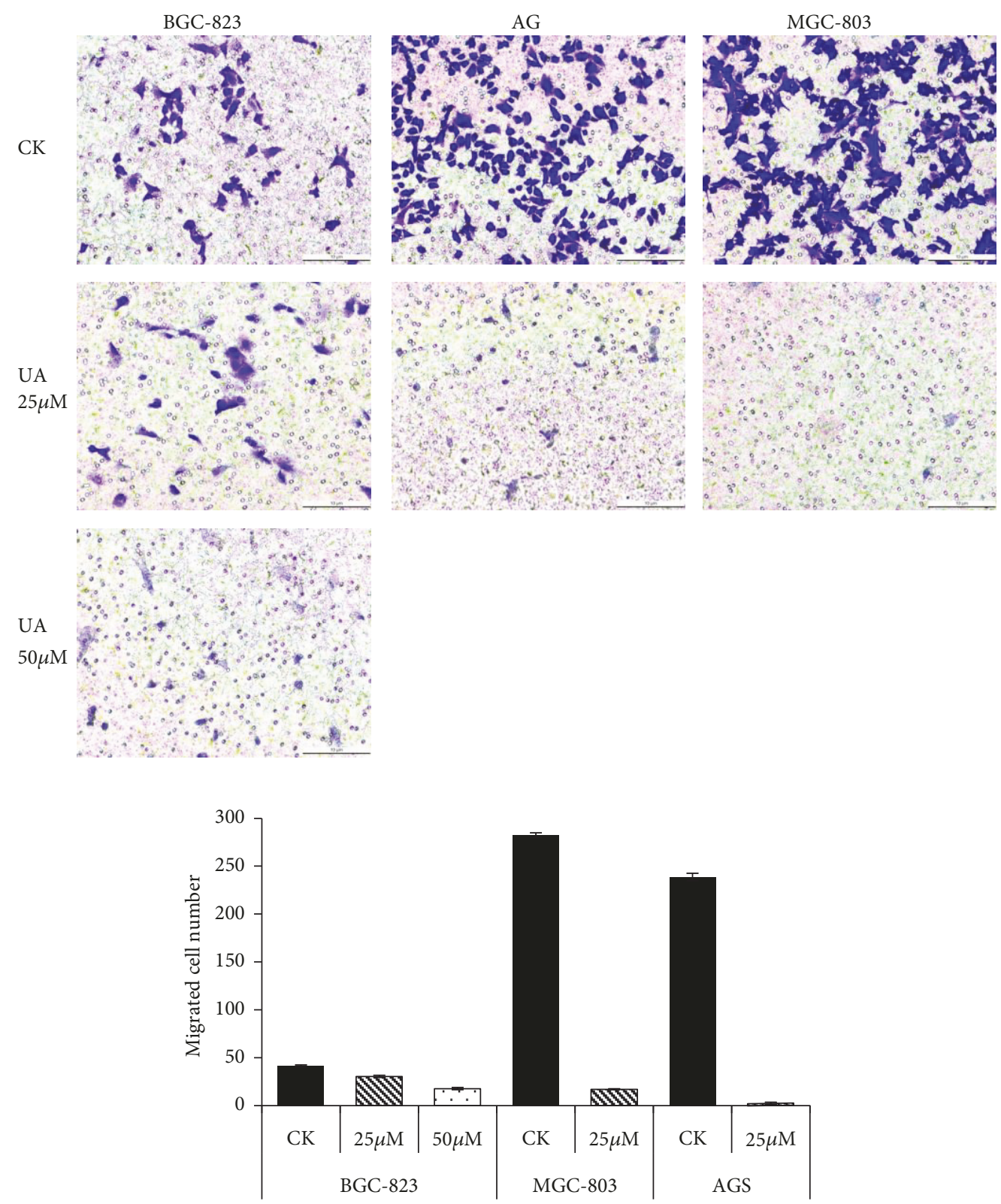

FIGURE 4: UA suppressed cell migration in BGC-823, MGC-803, and AGS Cells. Note: CK: cell lines without treatment; $25 \mu \mathrm{M}: \mathrm{CK}+25 \mu \mathrm{mol} / \mathrm{L}$ $\mathrm{UA} ; 50 \mu \mathrm{M}: \mathrm{CK}+50 \mu \mathrm{mol} / \mathrm{L} \mathrm{UA}$.

MGC-803 cells migrated significantly at the density of $1.5 \sim$ $2 \times 10^{4}$ cells/well, while HGC-27 and NCI-N87 cells showed no distinct migration even at the density of $2 \times 10^{4}$ cells/well. Our previous study showed that BGC-823 cells migrated significantly under the condition of $5 \times 10^{4}$ cells/well. Therefore, AGS, MGC-803, and BGC-823 cells were selected for further experiments.

3.3. UA Suppressed Cell Migration and EMT Related Protein Expressions in MGC-803 and BGC-823 Cells. As shown in Figure 4, UA $(25-50 \mu \mathrm{mol} / \mathrm{L})$ significantly inhibited BGC-823 cell migration in dose-dependent manners. $25 \mu \mathrm{mol} / \mathrm{L} \mathrm{UA}$ had obvious inhibitory effect on the migration of AGS and
MGC-803 cells, but $50 \mu \mathrm{mol} / \mathrm{L}$ UA damaged the two groups of cells, leading to the inability of subsequent experiments.

The expressions of EMT related proteins were examined by Western blot. As shown in Figure 5, both $25 \mu \mathrm{mol} / \mathrm{L}$ and $50 \mu \mathrm{mol} / \mathrm{L}$ UA decreased the levels of N-Cadherin, Snail, Vimentin, and Twist in BGC-823 cells. $25 \mu \mathrm{mol} / \mathrm{L}$ UA decreased the levels of N-Cadherin, Vimentin, and Twist in MGC- 803 cells. $50 \mu \mathrm{mol} / \mathrm{L}$ UA damaged the cells too much to obtain corresponding result in MGC-803 cells.

3.4. UA Targeted Axl/NF- $\kappa B$ Pathway in BGC-823 Cells. To investigate the mechanism on how UA regulates EMT, the expressions of key proteins in $\mathrm{Axl} / \mathrm{NF}-\kappa \mathrm{B}$ pathway were 

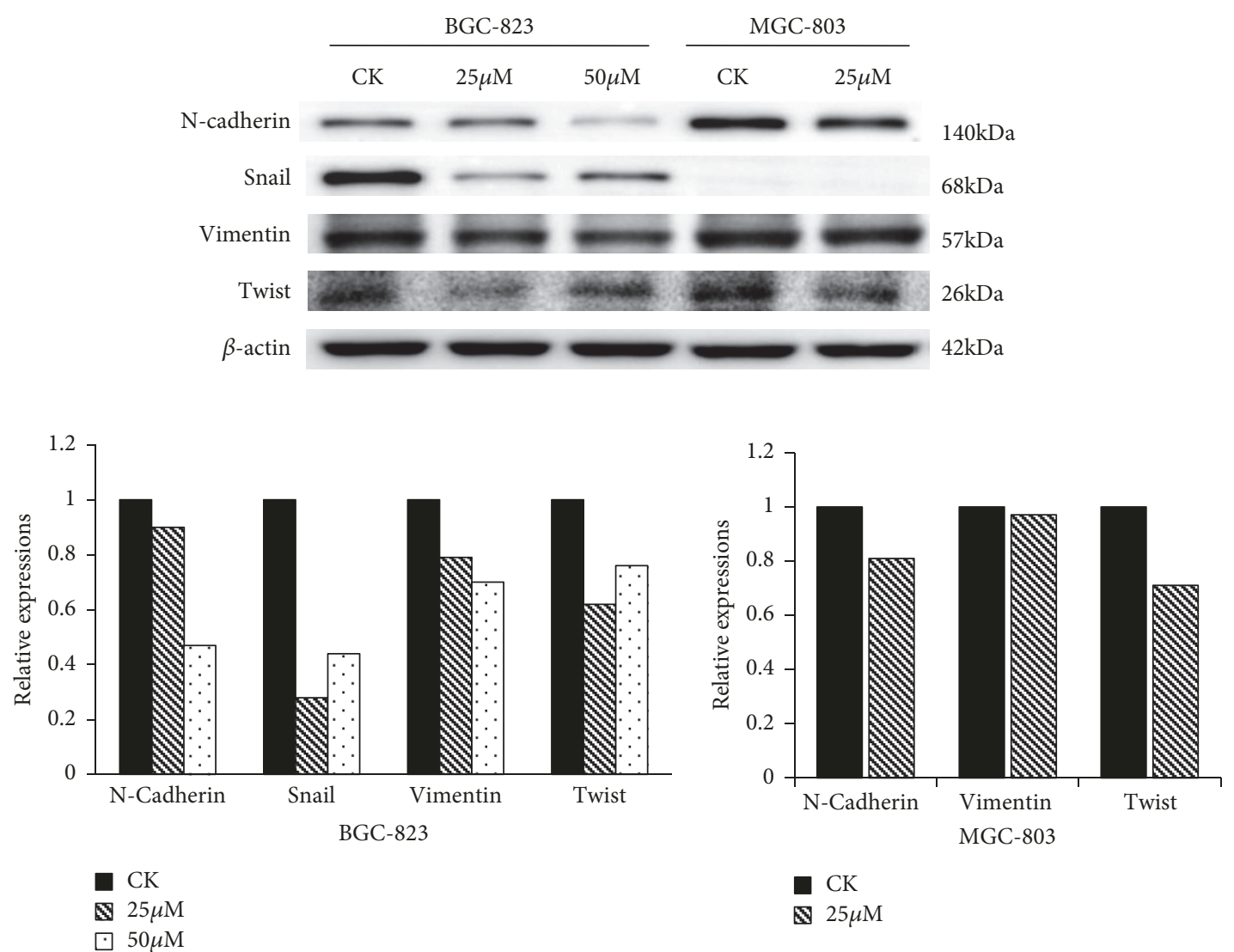

Figure 5: UA inhibited EMT related protein expressions in MGC-803 and BGC-823 cells. Note: CK: cell lines without treatment; $25 \mu \mathrm{M}$ : $\mathrm{CK}+25 \mu \mathrm{mol} / \mathrm{L} \mathrm{UA} ; 50 \mu \mathrm{M}: \mathrm{CK}+50 \mu \mathrm{mol} / \mathrm{L} \mathrm{UA}$.

examined by Western blot. As shown in Figure 6, UA decreased the levels of $\mathrm{p}-\mathrm{Axl}, \mathrm{p}-\mathrm{NF}-\kappa \mathrm{B}$, and $\mathrm{p}-\mathrm{IKK} \alpha / \beta$, while increasing the levels of $\mathrm{Axl}, \mathrm{NF}-\kappa \mathrm{B}$, and $\mathrm{IKK} \alpha / \beta$, and the values of $\mathrm{p}-\mathrm{Axl} / \mathrm{Axl}, \mathrm{p}-\mathrm{IKK} / \mathrm{IKK}$, and $\mathrm{p}-\mathrm{NF}-\kappa \mathrm{B} / \mathrm{NF}-\kappa \mathrm{B}$ were decreased. These results indicate that phosphorylations of $\mathrm{Axl}, \mathrm{IKK}$, and NF- $\kappa \mathrm{B}$ have been inhibited by UA in BGC-823 cells.

3.5. UA Inhibited the Expressions of EMT Related Proteins in Mouse GC Xenograft Model. Expressions of NCadherin and Snail in mouse GC xenograft model were examined by immunohistochemical analysis. As shown in Figure 7, compared with model group, the levels of $\mathrm{N}$ Cadherin and Snail were significantly decreased in UA group $(\mathrm{P}<0.01)$.

3.6. Inhibitory Effects of $U A$ on $A x l / N F-\kappa B$ Pathway in Mouse GC Xenograft Model. The key proteins in Axl/NF- $\kappa \mathrm{B}$ pathway were examined by Western blot in mouse GC xenograft model. As shown in Figure 8, compared with model group, UA downregulated the expressions of Axl, p-Axl, IKK $\alpha / \beta$, and $\mathrm{p}-\mathrm{IKK} \alpha / \beta$, and the values of $\mathrm{p}$-Axl/Axl and $\mathrm{p}-\mathrm{IKK} / \mathrm{IKK}$ significantly decreased $(\mathrm{P}<0.05)$. These results indicate that the phosphorylations of Axl and IKK have been inhibited by UA.

\section{Discussion}

UA is a pentacyclic triterpene compound and exists in medicinal herbs such as Oldenlandia diffusa and Radix actinidiae. It has the effects of anti-inflammatory, antioxidant, and antitumor [10]. Studies show that UA inhibits growth of tumor cells through multiple functions, such as cytotoxicity [11], induction of apoptosis [12], and prevention of angiogenesis [13]. In this study, different concentrations of UA were applied to various GC cell lines, and its resistance effects were observed. The results show that UA distinctly inhibited the proliferation of BGC-823 and HGC-27 cells in dose-dependent manners. UA significantly inhibited the migration of BGC-823, AGS, and MGC-803 cells. UA induced apoptosis of BGC-823 cells. In conclusion, UA can inhibit cell proliferation and migration, while inducing cell apoptosis of GC cells. Results are consistent with previous reports $[9,10]$.

Metastasis is the leading cause of cancer deaths. Attenuation of intercellular adhesion and enhancement of cellular activity are the basis of tumor invasion and metastasis [14]. EMT plays a crucial role in the genesis, invasion, and metastasis of various tumors. In EMT process, epithelial cells are converted into mesenchymal cells, causing the loss of cell-cell adhesion and the cell polarity, by which means cells acquired migratory and invasive properties [15]. Studies have confirmed that EMT is closely related to the 

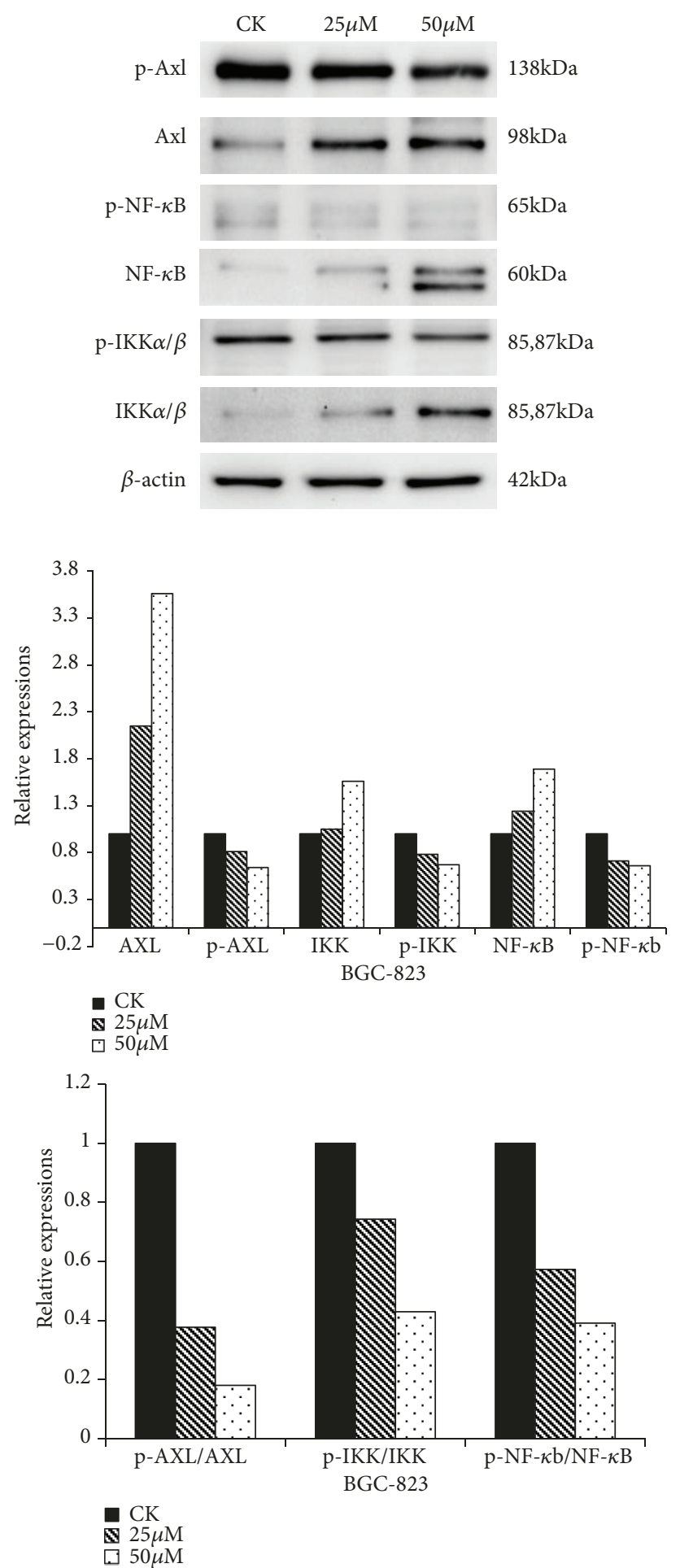

Figure 6: UA targeted Axl/NF- $\kappa B$ pathway in BGC-823 cells. Note: CK: cell lines without treatment; $25 \mu \mathrm{M}$ : CK+25 $\mu \mathrm{mol} / \mathrm{L}$ UA; $50 \mu \mathrm{M}$ : $\mathrm{CK}+50 \mu \mathrm{mol} / \mathrm{L} \mathrm{UA}$.

invasion and metastasis of GC [16]. During EMT, cadherin switches from E-cadherin to N-Cadherin; thus the upregulated expression of $\mathrm{N}$-Cadherin is considered important EMT biomarkers [17]. Vimentin is a kind of mesenchymal protein that exists in mesenchymal cells. The activation of
Vimentin regulates cytoskeletal protein and cell adhesion, which leads to the occurrence of EMT [18]. Snail, Slug, Smuc, ZEB, and Twist are the upstream transcription factors of EMT; they can competitively bind E-box sequences and cause epigenetic silence of E-cadherin gene, therefore promoting 

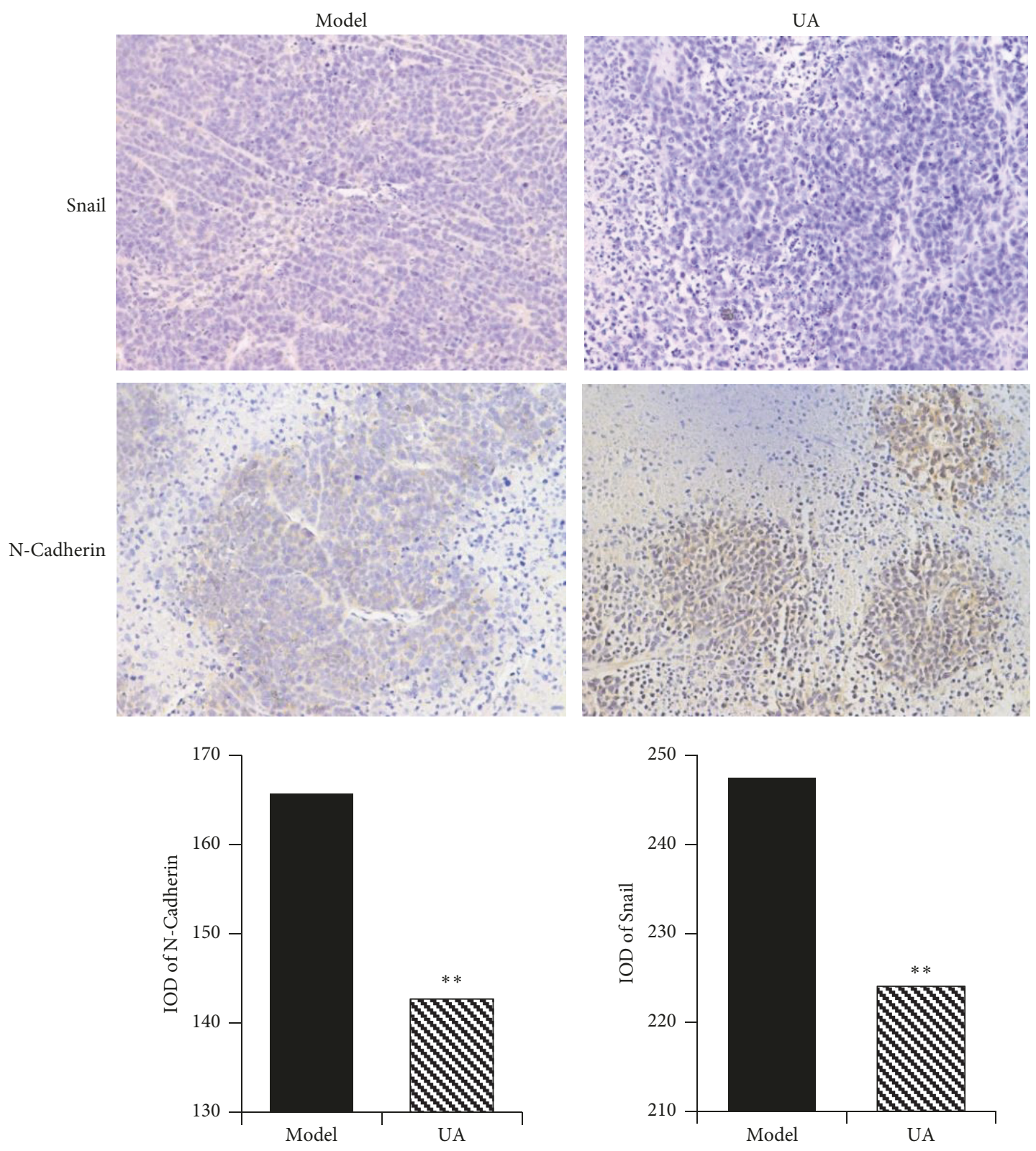

FIGURE 7: UA inhibited the expression of EMT related proteins in mouse GC xenograft model. Note: compared with model group, $* * \mathrm{P}<0.01$.

tumor metastasis [18]. In this study, we observed the effects of UA on the expressions of EMT related proteins. Results show that $25 \mu \mathrm{mol} / \mathrm{L}$ UA decreased the levels of N-Cadherin, Vimentin, Snail, and Twist in BGC-823 and MGC-803 cells. UA significantly reduced N-Cadherin and Snail expressions in mouse GC xenograft model. The results verified the inhibition effects of UA on EMT in GC from both in vivo and in vitro.

EMT is regulated by many signaling pathways. Axl is a member of receptor tyrosine kinase family and involves in the regulation of cell adhesion, proliferation, and cell transformation [19]. The overexpression of Axl can increase the invasiveness of GC [20]; the effect is related to induction of EMT [21, 22]. Breast cancer cells with overexpression of Axl have mesenchymal cellular phenotype; it does not rely on the existence of Axl's ligand Gas6. The application of AxlshRNA or Axl inhibitor MP470 can inhibit Axl expression, cells transferred to epithelial-like phenotype, and the EMT phenotype reversed [23]. As a downstream transcription factor of Axl, the sustained activation of NF- $\kappa \mathrm{B}$ has the effect of promoting EMT [24]. Kiefel $\mathrm{H}$ et al. blocked Axl on the surface of breast cancer cells; the activity of NF- $\kappa$ B pathway had decreased [25]. Huber et al. found that inhibition of $\mathrm{NF}-\kappa \mathrm{B}$ could block EMT and affect epithelial plasticity and metastasis of breast cancer; on the contrary, activation of NF$\kappa \mathrm{B}$ promotes EMT in breast cancer cells [26]. In the resting state of most cells, NF- $\kappa \mathrm{B}$ integrates with its inhibitor $\mathrm{I} \kappa \mathrm{B}-\alpha$; under the activation of kinase IKK $\alpha$, IKK $\beta$, and IKK $\gamma, \mathrm{I} \kappa \mathrm{B}-\alpha$ was phosphorylated and degraded, which expose the nuclear localization sequence of $\mathrm{NF}-\kappa \mathrm{B}$ and promote the activity of 

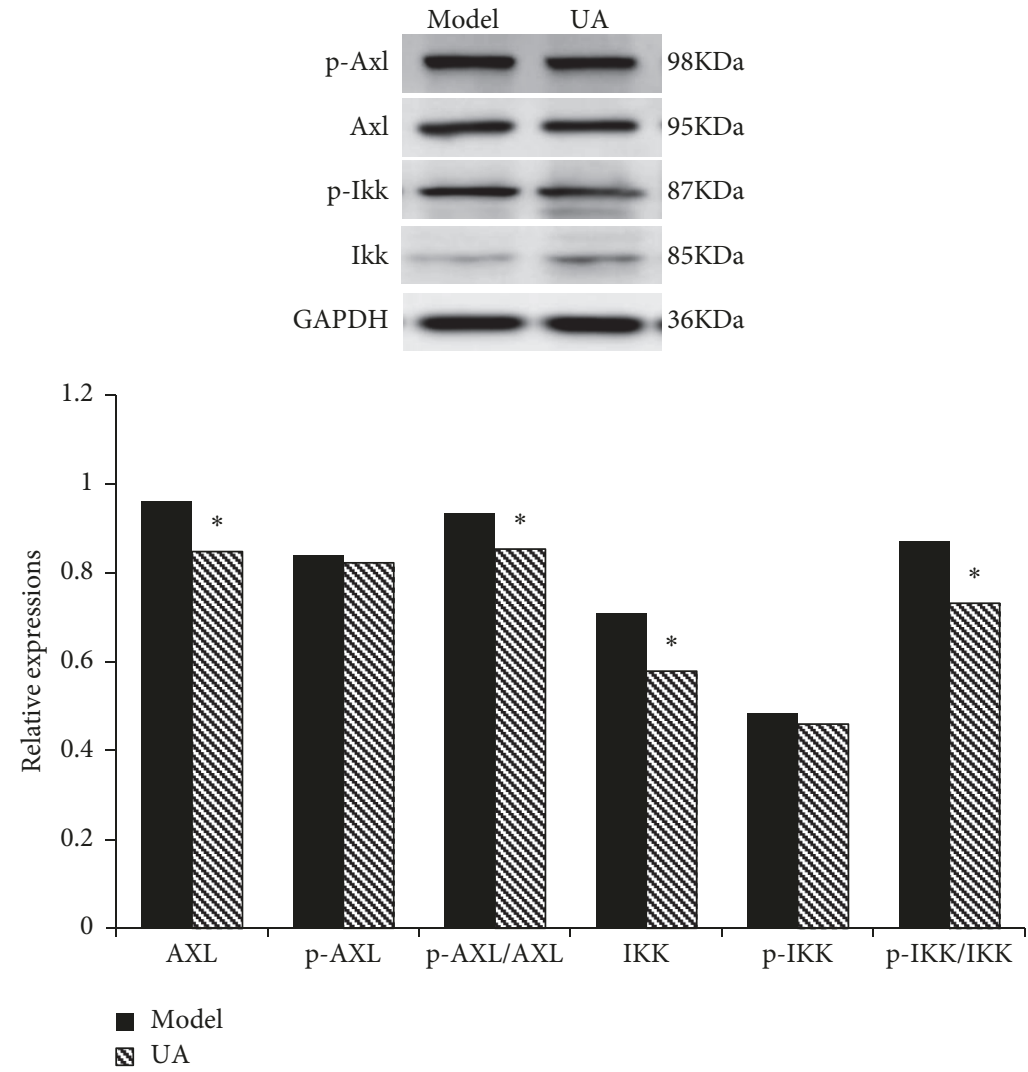

FiguRE 8: Inhibitory effects of $U A$ on $A x l / N F-\kappa B$ pathway in mouse GC xenograft model. Note: compared with model group, $* \mathrm{P}<0.05$.

EMT. Shishodia et al. found that UA can inhibit IKK $\alpha$ and p65 phosphorylation, leading to the suppression of NF- $\kappa \mathrm{B}$ activation induced by various carcinogens [27]. To further explore the mechanism of UA on EMT, we observed the effects of UA on expressions of key proteins in Axl/ NF$\kappa \mathrm{B}$ pathway. Results show that $25 \mu \mathrm{mol} / \mathrm{L}$ UA decreased the levels of $\mathrm{p}-\mathrm{Axl}, \mathrm{p}-\mathrm{IKK} \alpha / \beta$, and $\mathrm{p}-\mathrm{NF}-\kappa \mathrm{B}$ in BGC-823 cells, and it significantly decreased the $\mathrm{p}$-Axl and $\mathrm{p}$-IKK in mouse GC xenograft model. The results indicate that the inhibitory effects of UA on EMT may be associated with the regulation of $\mathrm{Axl} / \mathrm{NF}-\kappa \mathrm{B}$ signaling pathway.

In this study, $50 \mu \mathrm{mol} / \mathrm{L}$ UA damaged MGC-803 and AGS cells too much to proceed with subsequent experiments; further exploration of effective dose of UA is necessary.

\section{Conclusion}

UA can effectively inhibit the proliferation and migration and induce apoptosis of gastric cancer cells. The antitumor effect of UA is conducted by EMT inhibition, which may be associated with the regulation of $\mathrm{Axl} / \mathrm{NF}-\kappa \mathrm{B}$ signaling pathway.

\section{Abbreviations}

EMT: Epithelial-mesenchymal transition

UA: Ursolic acid

GC: Gastric carcinoma.

\section{Data Availability}

The images of this study are included within the article. The datasets used to support the findings of this study are available from the corresponding author upon request.

\section{Conflicts of Interest}

The authors declare that they have no conflicts of interest in this work.

\section{Authors' Contributions}

Jinxia $\mathrm{Li}$ performed the experiments, analyzed the data, and drafted the manuscript; Chunyan Du performed the experiments and polished the manuscript; Li Shen designed the research and provided technical guidance. All authors read and approved the final manuscript.

\section{Acknowledgments}

This research is supported by the National Natural Science Foundation of China (Grant No. 81873276), Beijing Municipal Natural Science Foundation (Grant No. 7172147), National Natural Science Foundation for Young Scientists of China (Grant No. 81403199), and Fundamental Research Funds for the Central Public Welfare Research Institutes (Grant No. YZ-1856). 


\section{References}

[1] I. Gomceli, B. Demiriz, and M. Tez, "Gastric carcinogenesis," World Journal of Gastroenterology, vol. 18, no. 37, pp. 5164-5170, 2012.

[2] J. Wang, S. D. Tian, and X. Y. Chen, "Progress of TCM in the treatment of advanced gastric cancer," World Journal of Integrated Traditional and Western Medicine, vol. 4, no. 8, pp. 596-600, 2009.

[3] R. Seevaratnam, A. Bocicariu, R. Cardoso et al., "How many lymph nodes should be assessed in patients with gastric cancer? a systematic review," Gastric Cancer, vol. 15, supplement 1, pp. S70-S88, 2012.

[4] J. M. Lee, S. Dedhar, R. Kalluri, and E. W. Thompson, "The epithelial-mesenchymal transition: new insights in signaling, development, and disease," The Journal of Cell Biology, vol. 172, no. 7, pp. 973-981, 2006.

[5] L. Zhao, W. Li, W. Zang et al., "JMJD2B promotes epithelialmesenchymal transition by cooperating with $\beta$-catenin and enhances gastric cancer metastasis," Clinical Cancer Research, vol. 19, no. 23, pp. 6419-6429, 2013.

[6] L.-L. Zang, B.-N. Wu, Y. Lin, J. Wang, L. Fu, and Z.-Y. Tang, "Research progress of ursolic acid's anti-tumor actions," Chinese Journal of Integrative Medicine, vol. 20, no. 1, pp. 72-79, 2012.

[7] F. Xiang, C. Pan, Q. Kong et al., "Ursolic acid inhibits the proliferation of gastric cancer cells by targeting miR-133a," Oncology Research : Featuring Preclinical and Clinical Cancer Therapeutics, vol. 22, no. 5-6, pp. 267-273, 2014.

[8] A. Feng and Q. S. Zhou, "Research of Ursolic acid inhibits cell invasiveness by suppressing the COX-2 expression in HGC-27 gastric cancer cells," Chinese Journal of Gastroenterology and Hepatology, vol. 25, no. 2, pp. 184-187, 2016.

[9] X. Wang, F. Zhang, L. Yang et al., "Ursolic acid inhibits proliferation and induces apoptosis of cancer cells in vitro and in vivo," Journal of Biomedicine and Biotechnology, vol. 2011, Article ID 419343, 8 pages, 2011.

[10] L. López-Hortas, P. Pérez-Larrán, M. J. González-Muñoz, E. Falqué, and H. Domínguez, "Recent developments on the extraction and application of ursolic acid. a review," Food Research International, vol. 103, pp. 130-149, 2018.

[11] M. Ganbold, J. Barker, R. Ma, L. Jones, and M. Carew, "Cytotoxicity and bioavailability studies on a decoction of Oldenlandia diffusa and its fractions separated by HPLC," Journal of Ethnopharmacology, vol. 131, no. 2, pp. 396-403, 2010.

[12] W. Huang, J. Huang, D. Zhang, R. Zhang, and Z. Liao, "Study on anti-invasive effect and apoptosis induction of pentacyclic triterpenoid in human lung cancer cells," Chinese Journal of Lung Cancer, vol. 6, no. 4, pp. 254-257, 2003.

[13] M. Kanjoormana and G. Kuttan, "Antiangiogenic activity of ursolic acid," Integrative Cancer Therapies, vol. 9, no. 2, pp. 224$235,2010$.

[14] J. Baselga, J. Cortés, S.-B. Kim et al., "Pertuzumab plus trastuzumab plus docetaxel for metastatic breast cancer," The New England Journal of Medicine, vol. 366, no. 2, pp. 109-119, 2012.

[15] H. Easwaran, H.-C. Tsai, and S. B. Baylin, "Cancer epigenetics: tumor heterogeneity, plasticity of stem-like states, and drug resistance," Molecular Cell, vol. 54, no. 5, pp. 716-727, 2014.

[16] Z. Peng, C.-X. Wang, E.-H. Fang, G.-B. Wang, and Q. Tong, "Role of epithelial-mesenchymal transition in gastric cancer initiation and progression," World Journal of Gastroenterology, vol. 20, no. 18, pp. 5403-5410, 2014.
[17] J. P. Their, "Epithelial-mesenchymal transitions in tumor progression," Nature Reviews Cancer, vol. 2, no. 6, pp. 442-454, 2002.

[18] H. D. Zhang, Y. Huang, and H. W. Li, "Research progress of epithelial-mesenchymal transition," Chinese Journal of Modern Medicine, vol. 21, no. 31, pp. 3907-3911, 2011.

[19] J. P. O’Bryan, R. A. Frye, P. C. Cogswell et al., “A transforming gene isolated from primary human myeloidleukemia cells, encodes a novel receptor tyrosinekinase," Molecular Cell Biology, vol. 11, no. 10, pp. 5016-5031, 1991.

[20] C. W. Wu, A. F. Li, C. W. Chi et al., "Clinicalsignificance of AXL kinase family in gastric cancer," Anticancer Research, vol. 22, no. 2B, pp. 1071-1078, 2002.

[21] S. Thomson, F. Petti, I. Sujka-Kwok et al., "A systems view of epithelial-mesenchymal transition signaling states," Clinical \& Experimental Metastasis, vol. 28, no. 2, pp. 137-155, 2011.

[22] M. L. Franco-Chuaire, M. C. Sánchez-Corredor, and L. Chuaire-Noack, "Epithelial-mesenchymal transition (EMT): Principles and clinical impact in cancer therapy," Investigacion Clinica (Venezuela), vol. 54, no. 2, pp. 186-205, 2013.

[23] C. Gjerdrum, C. Tiron, T. Høiby et al., "Axl is an essential epithelial-to-mesenchymal transition-induced regulator of breast cancer metastasis and patient survival," Proceedings of the National Acadamy of Sciences of the United States of America, vol. 107, no. 3, pp. 1124-1129, 2010.

[24] C. Min, S. F. Eddy, D. H. Sherr, and G. E. Sonenshein, "NF- $\kappa$ B and epithelial to mesenchymal transition of cancer," Journal of Cellular Biochemistry, vol. 104, no. 3, pp. 733-744, 2008.

[25] H. Kiefel, S. Bondong, M. Pfeifer et al., "EMT-associated upregulation of L1CAM provides insights into L1CAM-mediated integrin signalling and NF- $\kappa \mathrm{B}$ activation," Carcinogenesis, vol. 33, no. 10, pp. 1919-1929, 2012.

[26] M. A. Huber, N. Azoitei, B. Baumann et al., "NF- $\kappa$ B is essential for epithelial-mesenchymal transition and metastasis in a model of breast cancer progression," The Journal of Clinical Investigation, vol. 114, no. 4, pp. 569-581, 2004.

[27] S. Shishodia, S. Majumdar, S. Banerjee et al., "Ursolic acid inhibits nuclear factor-kappaB activation induced by carcinogenic agents through suppression of IkappaBalpha kinase and p65 phosphorylation: correlation with down-regulation of cyclooxygenase 2, matrix metalloproteinase 9, and cyclin D1," Cancer Research, vol. 63, no. 15, pp. 4375-4383, 2003. 


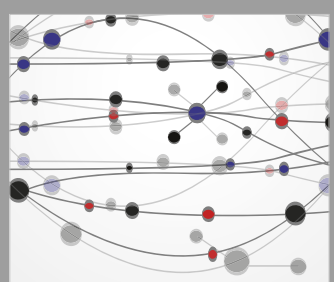

The Scientific World Journal
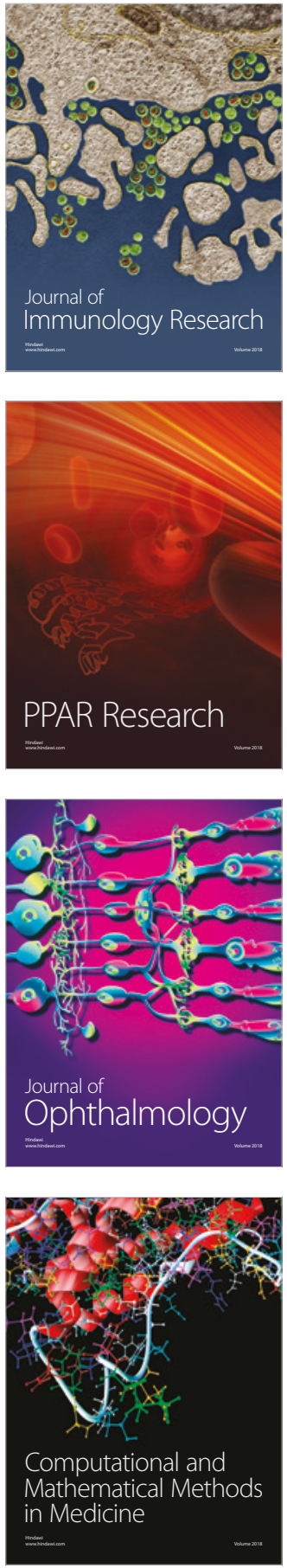

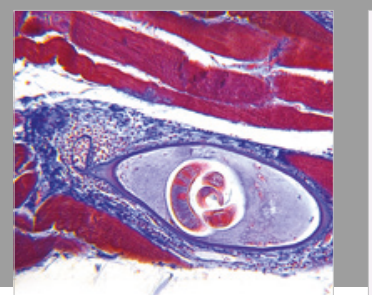

Gastroenterology Research and Practice

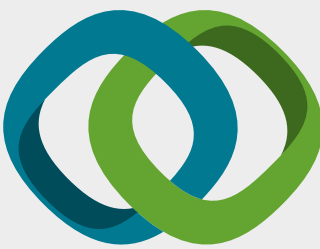

\section{Hindawi}

Submit your manuscripts at

www.hindawi.com
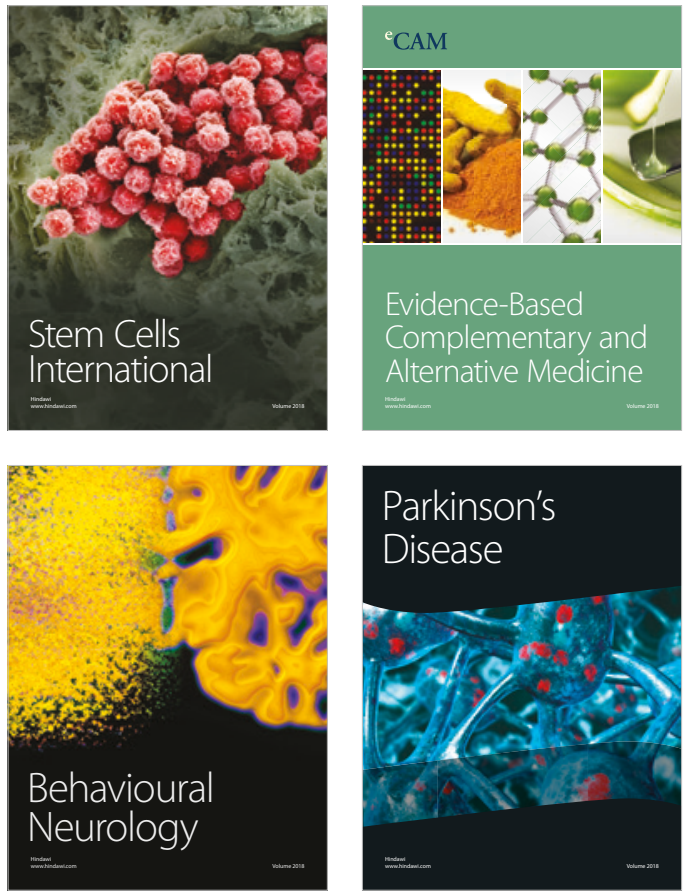

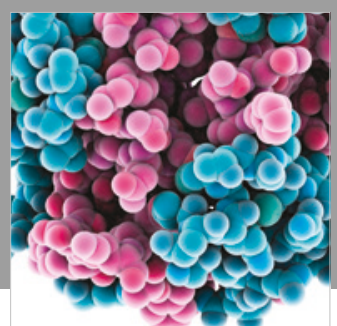

ournal of

Diabetes Research

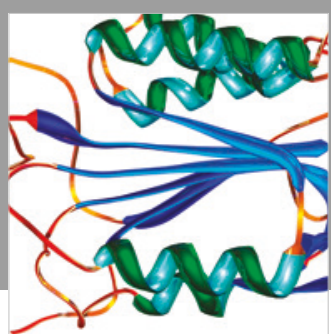

Disease Markers
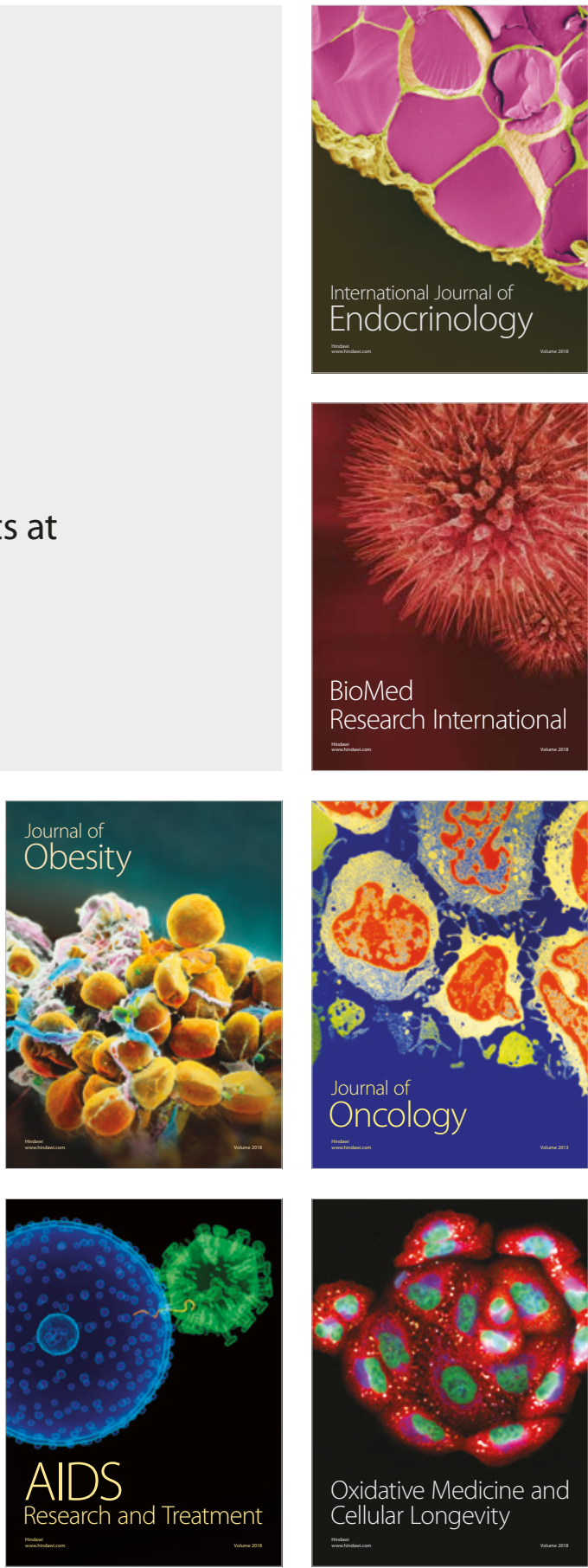